\title{
Chapter 11 \\ Knotting the Safety Net. A Multi-Actor Family Network Approach in Divorce Research
}

\author{
Vera de Bel and Dries Van Gasse
}

\begin{abstract}
Drawing on three theories in sociology, this chapter presents a theoretical framework for studying the consequences of parental divorce for the structure of relationships within the nuclear family and between nuclear and extended family members. First, interdependence as defined in family systems theory (FST) is explained. Second, the configurational approach (CA) is introduced. CA stresses the individual perspective in defining the family network and the non-static influence of configurations on the individual. Empirically, CA requires the collection of ego (personal) network data about family members and their relationships, the socalled Family Network Method (FNM). Third, the concept of a sharing group (SG) is introduced. SGs are characterized by the joint production of a common good by groups of individuals, subject to three types of interdependence: functional, structural and cognitive. Building on insights from FST and CA, the Multi-Actor Family Network Approach (MAFNA) is introduced, which conceives of families as SGs. Next, methods for the empirical implementation of MAFNA, requiring the collection of information about all family members and their relationships, are sketched, as well as social network analysis techniques for such data. Finally, the chapter discusses what kind of answers and questions in divorce research may be addressed using MAFNA.
\end{abstract}

Keywords Divorce · Family networks · Social networks · Interdependence · Resilience $\cdot$ Family well-being

\footnotetext{
V. de Bel $(\bowtie)$

University of Groningen, Groningen, The Netherlands

e-mail: v.de.bel@rug.nl

D. Van Gasse

University of Antwerp, Antwerp, Belgium

e-mail: Dries.VanGasse@uantwerpen.be 


\subsection{Introduction}

The divorce rate in Europe has doubled over the last 50 years (Eurostat 2019). In 2007 , roughly $15 \%$ of all children in countries such as the Netherlands and Belgium were growing up in single-parent households (OECD 2011). Although previous research has extensively studied the consequences of parental divorce for children (e.g., Amato 2010, 2014; Amato and Keith 1991; Emery and Forehand 1996; Hetherington and Stanley-Hagan 1999; Kelly and Emery 2003), for the divorcing parents (e.g., Amato 2000; Kitson and Morgan 2006), and for the grandparental generation (e.g., Jappens and Van Bavel 2016; Westphal et al. 2015), the consequences of parental divorce for the relationships within the nuclear family, i.e., parents and children, and between nuclear and extended family members, i.e., grandparents and aunts/uncles, have not been studied as such. This is remarkable because relationships with extended family members may not only be affected by the parental divorce (e.g., Ahrons 2007), but extended family members also form the knots in the nuclear family's safety net and therefore contribute to family resilience in families that experience divorce (Black and Lobo 2008; Hess and Camara 1979).

A well-known theoretical approach in studying the structure of relationships within the nuclear family, and between nuclear and extended family members, is the Family Systems Theory (FST) (Cox and Paley 1997; Minuchin 1974). As explained in Sect. 11.2, FST is a logical starting point for MAFNA because it acknowledges the interdependence between family relationships. Following this, the four pillars of the configurational approach (CA) are introduced. In addition to interdependence, CA stresses the individual perspective in defining the family network and the - nonstatic - influence of family configurations on the individual. When applied empirically, CA requires the collection of ego (personal) network data about family members and their relationships, which is called the Family Network Method (FNM) (Widmer 2016; Widmer et al. 2013). Further to this, the concept of a sharing group (SG) is introduced. Sharing groups are characterized by the joint production of a common good by groups of individuals, subject to three types of interdependence: functional, structural, and cognitive (Lindenberg 1997, 2015). Building on the insights from FST and CA, Sect. 11.3 introduces the Multi-Actor Family Network Approach (MAFNA) to apply the SG concept to families. Next, methods for the empirical implementation of MAFNA requiring the collection of information about all family members and their relationships is sketched, as well as the social network analysis techniques available for such data. Section 11.4 discusses what kind of answers and questions in divorce research may be addressed using MAFNA. 


\subsection{Theory}

\subsubsection{Family Systems Theory}

A basic assumption in Family Systems Theory (FST) (Cox and Paley 1997; Minuchin 1974) is that family relationships are interdependent, implying that the consequences of change in one relationship are not limited to this specific relationship but may also affect other family relationships. A way to understand interdependence is to consider smaller groups, called subsystems, within the larger family system. For example, the subsystem of the nuclear family exists within the larger family system that includes paternal and maternal family members. Since these subsystems consist of people who belong to the larger family system, subsystems interact and often overlap.

Regarding the family as a system deepens our understanding of how shocks, or stressors, affect the system. These shocks can be internal or external (Olson and Craddock 2000). Internal shocks like divorce are caused by the relational quality and/or strength of the family system, while external shocks like death have a cause outside the family system. In the context of divorce, it is reasonable to assume that relational tensions preceded the decision to get divorced and that these tensions are likely to continue afterwards. Hence, divorce may have a ripple effect in the family network. This means that chains of changing relationships affect not only the nuclear family but also members of the extended family.

Besides these shocks, there are also buffers. Like stressors, these buffers can be divided into external and external buffers. External buffers restrain families from deciding to divorce. For example, some countries are more family-centred, perhaps as a result of their family policies, and offer a context in which family systems are less likely to fall apart (Saxonberg 2013), while in others, culture and social networks influence divorce decisions (Afifi et al. 2013). Internal buffers prevent family members from disconnecting after divorce. The extended family system, for example, helps nuclear families to bounce back after divorce (Van Gasse and Mortelmans 2019). Because these transitions are longitudinal by nature, it is important to take dynamics, change and time into account in the analysis of changing family systems (Van Gasse and Mortelmans 2018).

Family systems theory was developed in response to psycho-analytical therapy in which "[...] therapists noted that it was more efficient to work to change the entire system than to try to change each constituent member of that system." (Fingerman and Bermann 2000, p. 10). The principles of FST are difficult to operationalize and therefore not often empirically tested (Whiteman et al. 2011). One of the proposed solutions for this lacuna is to divide the system into "smaller - empirically analysable - relational units" (de Bel et al. 2019, p. 3). However, dividing the system into smaller units results in the 'parts versus wholes' dilemma (see e.g., Segaric and Hall 2005): the system cannot be understood completely if one part, which is a system in itself, is studied in isolation. 


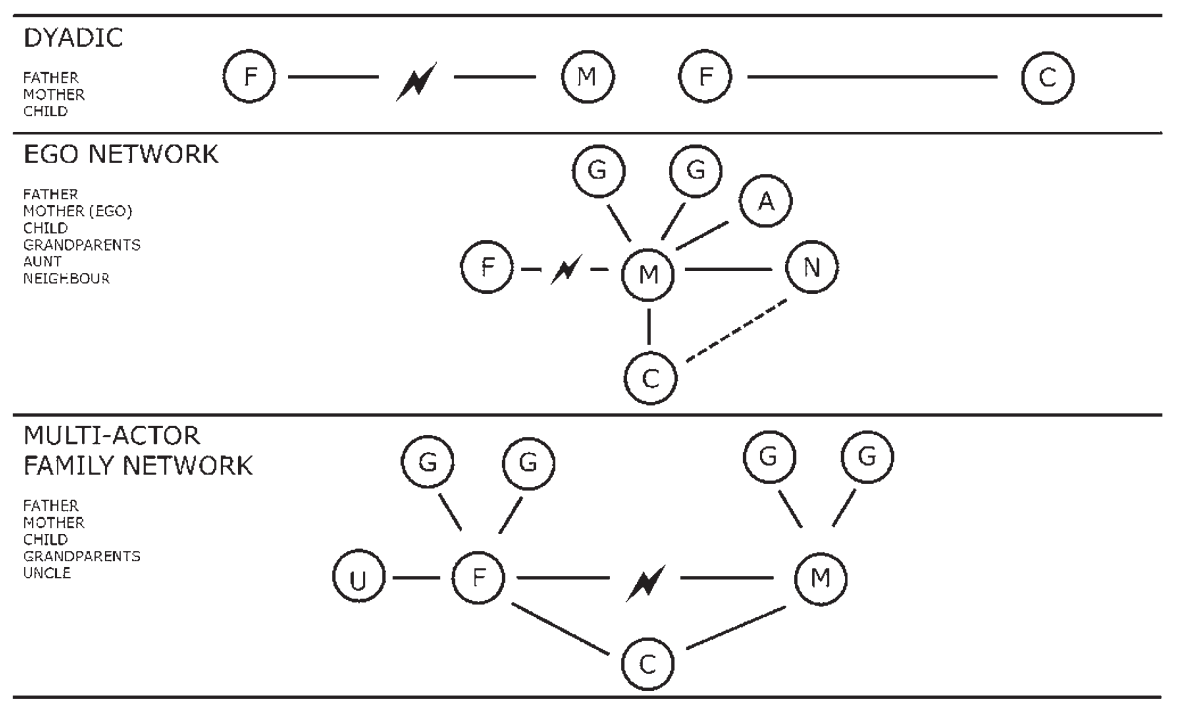

$\overline{---}$ = RELAT:ONAL NNFORMATION REPORTED BY AT LEAST ONE OE THE TWO CONNECTED ACTORS

Fig. 11.1 Schematic representation of the Multi-Actor Family Network Approach and its methodological alternatives. The lightning bolt represents parental divorce

This 'parts versus wholes' dilemma also becomes apparent in the upper part of Fig. 11.1. The dyadic approach analyses pairs of relationships; for example, the relationship between the two parents or the parent-child relationship. In a dyadic approach, the dependency on and between the surrounding relationships in the family network is not investigated and therefore the approach does not offer the ability to analyse the relational interdependence assumed in FST.

\subsubsection{The Configurational Approach}

The Configurational Approach (CA), developed by Widmer (2016), is based on Norbert Elias's notion of a configuration as "a structure of mutually oriented and dependent people" (Elias 1978, p. 261). When applied to families, CA rests on four pillars. First, the concept of a family is not necessarily limited to kin relatives. Friends and neighbours can also be considered part of the family. Second, CA considers the larger network of family relationships in which dyads are embedded. Third, CA assumes a mutual dependency between the individual level, such as individual choices or identity, and the structural level, i.e., the individual's perception of the network. Finally, family configurations are considered to be non-static and may change in response to time and space (Widmer 2019). 
Widmer et al. (2013) implement CA in the family network method (FNM). In this method, one central family member, the mother, is interviewed about her relationships to 'significant' family members, referred to as alters, and represented by the ego network approach in Fig. 11.1. The significant family members are not predefined but determined by ego, hence non-kin, such as friends and neighbours, can be included when mentioned as significant others. In addition, ego reports about the mutual relationships between the significant family members. In social network analysis, this is called an ego network with alter-alter information reported by ego (Robins 2015). Furthermore, information about the type of relationship such as emotional support or conflict, and family roles that the significant others fulfil is also collected.

Configurations characterize the composition and structure of the family network. By performing a factor analysis on the roles of and relationships between the significant family members, the family configurations that characterize the network can be outlined (Widmer et al. 2012). For example, the network may be focused on friends, family, the partner or siblings (Widmer et al. 2012, 2013). Additionally, it is possible to analyse whether certain configurations are more prominent in divorced or intact families (Widmer et al. 2012) or to what extent mothers embedded in certain configurations are socially or psychologically vulnerable (Widmer et al. 2013).

FNM has two major limitations. First, little information is collected on nonsignificant family members. For example, ego might not mention her ex-parents-inlaw as a significant family member. Consequently, it remains unknown whether the ex-parents-in-law are deceased, or are alive but insignificant to ego. Second, data collected according to FNM results in a one-sided observation of the system that we aim to understand, because it only reports the perception of ego and does not contain perceptions of the other family members.

To summarize our arguments so far: FST offers a natural starting point for explaining interdependence between family members and how the family can be regarded as a dynamic system when processing shocks like divorce. However, a methodological means of implementation that takes this interdependence into account does not yet exist. CA deepens our understanding by characterizing the family network by several compositional configurations and offers a methodological means of implementation by introducing the family network method (FNM) (Widmer 2016; Widmer et al. 2013). However, this method does not distinguish between non-significant and non-existent family members, and it only approaches the system from ego's perspective. A third approach, sharing groups (SG) and thus far not applied to family sociology, may provide further insight into the nature of interdependence within families by explaining the functioning of the family as the preservation, or joint production, of family well-being. The synthesis of these three theories results in the theoretical foundation of MAFNA, which is introduced after the theory section. 


\subsubsection{Families as a Sharing Group}

The concept of a sharing group (SG) (Lindenberg 1982, 1997, 2015) refers to a group of people who together produce a common good. Individuals operating on their own would not be able to produce this good, and are hence dependent on the other members of the group. The size of a sharing group depends on the number of people needed to produce the common good, and it is important that all members of the sharing group contribute in order to produce it.

Some goods require joint production, even in a market society with a high level of welfare, in order to produce the common good (Becker 2013; Lindenberg 1997). For example, as an SG, a sports team strives to produce the common good of winning a match, for which they make the joint production of training every week and preparing for the match. Highly specialized work teams may focus on the common good of developing a new product, which requires the joint production of daily discussion, aligning the members' tasks and sharing thoughts about their work (Fetchenhauer et al. 2006).

Although the notion of sharing groups has not previously been applied to family sociology, there is some theoretical overlap between the concepts introduced so far. According to Widmer (2019), Elias saw individuals as dependent on other individuals, forming configurations in which they fulfil each other's needs and provide each other with resources, a form of cooperation similar to the interdependence of joint production.

Sharing groups are characterized by multiple interdependencies between their members: functional, structural and cognitive (Lindenberg 1997, 2015). Functional interdependence means that all group members need to contribute to produce the common good. Structural interdependence, described as relational dependencies within groups, which can best be explained as not having to be directly connected in order to be affected by other relationships. Finally, sharing groups are characterized by cognitive interdependence, which refers to the interpersonal perceptions of role-related appropriate behaviour. In an organizational setting, this depends on a group member's perception of roles, for instance, managers and staff, relationships and tasks within the group, and what this person considers to be appropriate behaviour, for instance promoting an employee who performed well.

\subsection{The Multi-Actor Family Network Approach}

MAFNA is an extension and synthesis of the ideas presented in FST, CA and its methodological implementation, as well as an application of SG to the family context. Theoretically, it embraces the idea of interdependence between family members. The joint production of the common good of family well-being explains the functioning of the family, and takes into account the interdependencies that characterise families as sharing groups. Methodologically, just as CA was implemented in 
FNM, MAFNA can also be implemented in data collection (de Bel and van Duijn 2019).

If we apply the concept of SG to the context of the family, we must identify its common goal as the preservation of family well-being. An individual family member's well-being depends for a large part on the well-being of the other family members. Similarly to the 'parts versus wholes' dilemma (Segaric and Hall 2005) in FST, family well-being is more than the sum of all family members' individual well-being. Steverink et al. (2005) argue that (individual) well-being is produced by the multi-functionality of the relationships in the network, which can be interpreted that well-being will be highest if relationships fulfil multiple needs (Lindenberg, personal communication, October 17, 2018). In other words, the joint production, of family well-being, keeps the relationships active and, if necessary, activates one of its functions, namely to serve as a safety net. This may explain why, if parental divorce or other life course adversities occur, family well-being can still be preserved.

Functional interdependence in the context of the family implies that family wellbeing depends on the contribution of all members. If family members are not able to contribute, this will not only affect their own individual well-being, but also the well-being of the family as a whole. Structural interdependence in the context of the family implies that other family members may also be affected by the conflict in the parental relationship, which may endanger the joint production of family wellbeing. Structural and functional interdependence are distinguished as separate concepts, but are intrinsically entwined. In network analysis terms, this is referred to as mutual dependency between the structure of the network and individual level outcomes (Steglich et al. 2010). In families, it means that family well-being is affected by the structure of all family relationships, and that embeddedness in the family network affects individual family members' well-being. Individuals who feel well are more likely to 'give' more affection, thus strengthening the family relationships. Whereas family members who are having a hard time might turn to their family members for support. And if family relationships are supportive, people who are well embedded in the family network are likely to feel better.

Cognitive interdependence in the context of the family implies that family members have multiple roles. For example, family members normatively expect parents in their parental role to comply with the role-oriented normative pattern with respect to their children. However, parents are also children and siblings in their original nuclear family, and are expected by their parents and siblings to behave according to those roles as well. During the process of parental divorce, cognitive interdependence shifts because family roles and perceptions change. Divorce may lead to negative perceptions, justified or not, about other family members, which leads to certain relational behaviour that can potentially cause a vicious circle of worsening family relationships. Furthermore, divorced parents are no longer partners and have to give meaning to the new roles that they play in each other's lives. Their role as a (former) in-law family member most likely changes or disappears as well. Children and grandparents have to reconsider their roles: children have to position themselves 
with respect to two separate parents, while grandparents might be inclined to revert to their previous roles as caretakers in order to preserve family well-being.

The bottom part of Fig. 11.1 shows the multi-actor family network approach. The figure shows that the nuclear family (parents F-M and their child C) constitutes one subsystem in a larger family system. At the same time, both parents are part of their own nuclear family, i.e., the children's grandparents, aunts, and uncles, depicted by (G-G-F-U) on father's side and (G-G-M) on mother's side in Fig. 11.1. This approach results in more information about exchange in family relationships and, if the data are longitudinal, the consequences of change in the network following parental divorce for family well-being.

\subsubsection{The Delineation of Family Networks}

Instead of only asking ego about his/her relationships, in the multi-actor family network approach, multiple members of the family are asked to report about their relationships. In order to determine who these multiple informants should be, a meaningful delineation of the family network is needed. When delineating the network, it is important to strike a balance between inclusiveness and relevance. In theory, nuclear family networks can always be extended with first-degree, second-degree and more remote relatives, and hence can never be considered 'complete.' For the purpose of the multi-actor family network approach, individuals should only be included if they have a meaningful family relationship with the nuclear family network.

An important point to consider in the delineation of the family network is the position of the divorcing parents and the roles of the other family members in the network. Although all family members are related by blood or marriage, the - former - couple is most central in the network. The parental divorce makes the delineation of the family network even more important, where it is expected that the members of the family as a sharing group are concerned about the well-being of the children of the divorcing parents. Typically, these are the first-degree relatives of the divorcing parents, i.e. the nuclear families they come from.

Acknowledging that other people, like friends and neighbours, may also be important to family members and they might even feel like family (Widmer 2016, 2019; Widmer et al. 2013), the sharing group argument leads to a rather strict delineation of the family network consisting of parents, children, grandparents, aunts/ uncles, and potential stepfamily.

\subsubsection{Implementation}

A family survey instrument (or interview scheme) needs to be developed that retrieves family network data from multiple actors. The methods to retrieve such data may have a qualitative or quantitative focus, or both. Data with a quantitative 
focus can be collected using a survey instrument to be filled out by all (or at least several) family members (see the study by de Bel and van Duijn 2019). Data with a qualitative focus can be collected by interviewing multiple members of the same family about their family relationships (e.g., Van Parys et al. 2017 developed a multi-family member interview method).

At the individual level, family members' well-being can be assessed using several well-being measurement instruments. To assess the network, several relational measurements can be used. First, questions about proximity, like "who lives nearby?", and contact (face-to-face and phone/letter/digital) between the family members can be asked because they offer an opportunity for qualitative interpretation of family relationships, such as affection, support or conflict. Second, qualitative interpretations of family relationships are measured, such as affection (e.g., by asking: "to whom do you feel close?"), emotional ("with whom can you talk about emotional problems?"), material ("from who do you receive money or goods?"), and instrumental ("whom do you help with household tasks?") support. Differences between giving and receiving can be unravelled ("who can you go to for advice" or "who comes to you for advice?"). This way, different perceptions between family members can be compared. In addition, the parents, as central actors of the network, can be asked about their perception of the network ("which family members are not on speaking terms?").

Which social network analysis methods exactly are suitable for these data is a question that remains to be explored. We will briefly discuss which type of social network analysis models are eligible. Exponential random graph models and their extensions (Caimo and Friel 2014; Robins et al. 2007) might be suitable for comparing relational patterns between divorced and non-divorced family networks. If data are collected longitudinally and repeated measurements are available, statistical models that make it possible to study change in the network as well as change in individual attributes, such as well-being, can be used (Snijders et al. 2010; Steglich et al. 2010). Actor-based co-evolution models (Snijders et al. 2010; Steglich et al. 2010) enable us to analyse the mutual dependency between the individual level and the structural level.

\subsection{Conclusion and Discussion}

\subsubsection{Conclusion}

Extended family members have been under-studied in family and divorce research. This is remarkable because relationships with extended family members may not only be affected by the parental divorce (e.g., Ahrons 2007), but extended family members also form the knots in the nuclear family's safety net and therefore contribute to family resilience in families that experienced divorce (Black and Lobo 2008; Hess and Camara 1979). This chapter introduced MAFNA, which synthesizes 
three sociological theories. FST offers a natural starting point for explaining interdependence between family members and how the family can be regarded as a dynamic system when processing shocks such as divorce. However, a methodological implementation that takes this interdependence fully into account does not exist yet. CA deepens our understanding by characterizing the family network by several compositional configurations and offers a methodological implementation by introducing the family network method (FNM) (Widmer 2016; Widmer et al. 2013). This method, however, does not distinguish between non-significant and non-existent family members and it approaches the system from ego's perspective only. Seeing families as sharing groups enables us to study the joint production of the common good of family well-being and explains the functioning of the family, while being aware of the interdependencies that characterize families.

MAFNA aims to understand the family as a whole. It addresses the ontological question of what a family is by using all the different perspectives of the actors who are active in the structure of a family. The approach extends and synthesizes ideas developed in FST and CA by implementing the idea of sharing groups. MAFNA approaches change from the perspective of resilience: The extended family does not only function as a safety net, but also as a way to rebound. The approach is not limited to one methodological perspective, as both qualitative and quantitative methods are suitable for empirical analysis. Its main requirement is the thorough gathering of rich data in order to study the family network in transition after parental divorce.

\subsubsection{Discussion}

MAFNA may provide new insights into well-known research questions in the field of family and divorce research. Many studies have investigated how children's wellbeing is affected by parental divorce (e.g., Amato 2010, 2014; Amato and Keith 1991; Emery and Forehand 1996; Hetherington and Stanley-Hagan 1999; Kelly and Emery 2003). The first benefit of MAFNA in such research is that it leads to an understanding of the interdependence of well-being amongst various family members. Second, by collecting relational data between all family members, MAFNA makes it possible to investigate how an individual's well-being is associated with the relational structure formed by the various ties between family members (for example the relational structure a loyalty conflict, see the work of Amato and Afifi 2006). Third, MAFNA offers the ability to focus either on the network as a whole, or to specifically focus on one of the various family roles. Consequently, we can take into account the cognitive interdependence of well-being by investigating whether well-being is affected by changing family roles. This approach may provide a different answer to the question of how children's well-being is affected by the process of 'parentification' (e.g., Earley and Cushway 2002).

MAFNA may also provide an opportunity to answer new questions, such as how compensation mechanisms arise after parental divorce. For example, support offered by the uncle from father's side (U, Fig. 11.1) might become inaccessible for family 
members on mother's side if both parents maintain a negative relationship with each other. The child (C) can be seen as a natural bridging node between father's kin and mother's kin. In the period after divorce, the bridging function is at risk. The establishment or re-establishment of additional support ties between both sides of the family network (U-M) may compensate for the negative impact on well-being, offering new routes for exchange and maintaining family resilience.

Despite the interesting research questions that MAFNA can help us to answer theoretically, it should be noted that the collection of family network data is not easy, as explained in more detail by de Bel and van Duijn (2019). Approaching families, informing family members about the - sometimes sensitive - questions that they will be asked, and obtaining the informed consent of (preferably whole) families is difficult, especially in divorced families where, in accordance with the theory laid out in this chapter, the family system is likely to be less stable. This results in a higher risk of incomplete data due to family members being harder to reach and/or less willing to participate. It is clear that more research on implementing MAFNA in data collection is needed.

Acknowledgement This chapter was supported by funding of the Netherlands Organisation for Scientific Research (NWO) (Research Talent Grant project number 406-15-191) and the Centre for Population, Family and Health (CPFH) at the University of Antwerp and the Flemish Agency of Innovation and Entrepreneurship (Grant number: 140069), which enabled Open Access to this chapter.

\section{References}

Afifi, T. D., Davis, S., Denes, A., \& Merril, A. (2013). Analyzing divorce from cultural and network approaches. Journal of Family Studies, 19(3), 240-253.

Ahrons, C. R. (2007). Family ties after divorce: Long-term implications for children. Family Process, 46(1), 53-65. https://doi.org/10.1111/j.1545-5300.2006.00191.x.

Amato, P. R. (2000). The consequences of divorce for adults and children. Journal of Marriage and Family, 62(4), 1269-1287. https://doi.org/10.1111/j.1741-3737.2000.01269.x.

Amato, P. R. (2010). Research on divorce: Continuing trends and new developments. Journal of Marriage and Family, 72(3), 650-666. https://doi.org/10.1111/j.1741-3737.2010.00723.x.

Amato, P. R. (2014). The consequences of divorce for adults and children: An update. Društvena Istraživanja: Časopis Za Opća Društvena Pitanja, 23(1), 5-24.

Amato, P. R., \& Afifi, T. D. (2006). Feeling caught between parents: Adult children's relations with parents and subjective well-being. Journal of Marriage and Family, 68(1), 222-235. https:// doi.org/10.1111/j.1741-3737.2006.00243.x.

Amato, P. R., \& Keith, B. (1991). Parental divorce and the well-being of children: A meta-analysis. Psychological Bulletin, 110(1), 26-46. https://doi.org/10.1037/0033-2909.110.1.26.

Becker, G. S. (2013). The economic approach to human behavior. Chicago: The University of Chicago Press.

Black, K., \& Lobo, M. (2008). A conceptual review of family resilience factors. Journal of Family Nursing, 14(1), 33-55.

Caimo, A., \& Friel, N. (2014). Bergm: Bayesian exponential random graphs in R. Journal of Statistical Software, 61(2). https://doi.org/10.18637/jss.v061.i02. 
Cox, M. J., \& Paley, B. (1997). Families as systems. Annual Review of Psychology, 48, 243-267. https://doi.org/10.1146/annurev.psych.48.1.243.

de Bel, V., Kalmijn, M., \& van Duijn, M. A. J. (2019). Balance in family triads: How intergenerational relationships affect the adult sibling relationship. Journal of Family Issues, 40(18), 2707-2727. https://doi.org/10.1177/0192513X19860181.

de Bel, V., \& van Duijn, M. A. J. (2019). Collecting multi-actor family network data. University of Groningen: Department of Sociology.

Earley, L., \& Cushway, D. (2002). The parentified child. Clinical Child Psychology and Psychiatry, 7(2), 163-178. Retrieved from http://www.embase.com/search/results?subaction=viewrecord $\&$ from=export\&id=L34492259.

Elias, N. (1978). What is sociology? New York: Columbia University Press.

Emery, R. E., \& Forehand, R. (1996). Parental divorce and children's well-being: A focus on resilience. In Stress, risk, and resilience in children and adolescents: Processes, mechanisms, and interventions (pp. 64-99). New York: Cambridge University Press.

Eurostat. (2019). Crude marriage rate and crude divorce rate. Retrieved from https://ec.europa.eu/ eurostat/web/products-datasets/-/tps00206

Fetchenhauer, D., Flache, A., Lindenberg, S., \& Buunk, A. B. (2006). Solidarity and prosocial behavior: An integration of sociological and psychological perspectives. Dordrecht: Springer Science \& Business Media. https://doi.org/10.1007/0-387-28032-4.

Fingerman, K. L., \& Bermann, E. (2000). Applications of family systems theory to the study of adulthood. The International Journal of Aging and Human Development, 51(1), 5-29. https:// doi.org/10.2190/7TF8-WB3F-TMWG-TT3K.

Hess, R. D., \& Camara, K. A. (1979). Post-divorce family relationships as mediating factors in the consequences of divorce for children. Journal of Social Issues, 35(4), 79-96. https://doi. org/10.1111/j.1540-4560.1979.tb00814.x.

Hetherington, E. M., \& Stanley-Hagan, M. (1999). The adjustment of children with divorced parents: A risk and resiliency perspective. Journal of Child Psychology and Psychiatry and Allied Disciplines, 40(1), 129-140. https://doi.org/10.1017/S0021963098003394.

Jappens, M., \& Van Bavel, J. (2016). Parental divorce, residence arrangements, and contact between grandchildren and grandparents. Journal of Marriage and Family, 78(2), 451-467. https://doi.org/10.1111/jomf.12275.

Kelly, J. B., \& Emery, R. E. (2003). Children's adjustment following divorce: Risk and resilience perspectives. Family Relations, 52(4), 352-362.

Kitson, G. C., \& Morgan, L. A. (2006). The multiple consequences of divorce: A decade review. Journal of Marriage and the Family, 52(4), 913. https://doi.org/10.2307/353310.

Lindenberg, S. (1982). Sharing groups: Theory and suggested applications. The Journal of Mathematical Sociology, 9(1), 33-62. https://doi.org/10.1080/0022250X.1982.9989931.

Lindenberg, S. (1997). Grounding groups in theory: Functional, cognitive, and structural interdependencies. Advances in Group Processes, 14, 281-331.

Lindenberg, S. (2015). Groups, sociology of. In J. D. Wright (Ed.), International encyclopedia of the social \& behavioral sciences (2nd ed., pp. 434-440). Oxford: Elsevier.

Minuchin, S. (1974). In S. Minuchin (Ed.), Families \& family therapy. Cambridge, MA: Harvard University Press.

OECD. (2011). Families are changing. https://doi.org/10.1787/9789264098732-en.

Olson, D. H., \& Craddock, A. E. (2000). Circumplex model of marital and family systems. Journal of Family Therapy, 22, 144-167. https://doi.org/10.1080/01591487.1980.11004154.

Robins, G. (2015). In G. Robins (Ed.), Doing social network research: Network-based research desgin for social scientists. London: Sage.

Robins, G., Pattison, P., Kalish, Y., \& Lusher, D. (2007). An introduction to exponential random graph ( $\mathrm{p} *$ ) models for social networks. Social Networks, 29, 173-191. https://doi.org/10.1016/j. socnet.2006.08.002.

Saxonberg, S. (2013). From defamilialization to degenderization: Toward a new welfare typology. SocialPolicy\&Administration, 47(1),26-49.https://doi.org/10.1111/j.1467-9515.2012.00836.x. 
Segaric, C. A., \& Hall, W. A. (2005). The family theory-practice gap: A matter of clarity? Nursing Inquiry, 12(3), 210-218. https://doi.org/10.1111/j.1440-1800.2005.00270.x.

Snijders, T. A. B., van de Bunt, G. G., \& Steglich, C. E. G. (2010). Introduction to stochastic actorbased models for network dynamics. Social Networks, 32(1), 44-60. https://doi.org/10.1016/j. socnet.2009.02.004.

Steglich, C. E. G., Snijders, T., \& Pearson, M. (2010). Dynamic networks and behavior: Separating selection from influence. Sociological Methodology, 40(1), 329-393.

Steverink, N., Lindenberg, S., \& Slaets, J. P. J. (2005). How to understand and improve older people's self-management of wellbeing. European Journal of Ageing, 2(4), 235-244. https:// doi.org/10.1007/s10433-005-0012-y.

Van Gasse, D., \& Mortelmans, D. (2018). Scheiden doe je niet alleen. De rollen van het netwerk in de transitie naar alleenstaand ouderschap na scheiding. In I. Pasteels (Ed.), Families in transitie, transitie in families (pp. 231-256). Dordrecht: Kluwer Academic Publisher.

Van Gasse, D., \& Mortelmans, D. (2019). Jägermeister is our housewine. A qualitative study on the role of social networks in the resilience of single parent families after a transition to single parenthood (Manuscript in preparation).

Van Parys, H., Provoost, V., De Sutter, P., Pennings, G., \& Buysse, A. (2017). Multi family member interview studies: A focus on data analysis. Journal of Family Therapy, 39(3), 386-401. https:// doi.org/10.1111/1467-6427.12169.

Westphal, S. K., Poortman, A. R., \& Van der Lippe, T. (2015). What about the grandparents? Children's postdivorce residence arrangements and contact with grandparents. Journal of Marriage and Family, 77(2), 424-440. https://doi.org/10.1111/jomf.12173.

Whiteman, S. D., McHale, S. M., \& Soli, A. (2011). Theoretical perspectives on sibling relationships. Journal of Family Theory \& Review, 3(2), 124-139. https://doi. org/10.1111/j.1756-2589.2011.00087.x.

Widmer, E. D. (2016). Family configurations: A structural approach to family diversity. London: Routledge.

Widmer, E. D. (2019). Family and personal configurations. Retrieved from http://www.edwidmer. org/page-researcha

Widmer, E. D., Favez, N., Aeby, G., De Carlo, I., \& Doan, M. (2012). Capital social et coparentage dans les familles recomposées et de première union.

Widmer, E. D., Aeby, G., \& Sapin, M. (2013). Collecting family network data. International Review of Sociology, 23(1), 27-46. https://doi.org/10.1080/03906701.2013.771049.

Open Access This chapter is licensed under the terms of the Creative Commons Attribution 4.0 International License (http://creativecommons.org/licenses/by/4.0/), which permits use, sharing, adaptation, distribution and reproduction in any medium or format, as long as you give appropriate credit to the original author(s) and the source, provide a link to the Creative Commons license and indicate if changes were made.

The images or other third party material in this chapter are included in the chapter's Creative Commons license, unless indicated otherwise in a credit line to the material. If material is not included in the chapter's Creative Commons license and your intended use is not permitted by statutory regulation or exceeds the permitted use, you will need to obtain permission directly from the copyright holder.

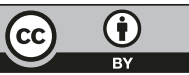

